\title{
Correlates of Financial Concerns and Symptoms of Depression and Posttraumatic Stress Disorder in Impoverished Urban-dwelling Individuals in Bangladesh During the COVID-19 Pandemic: Face-to-face Interview Findings
}

Md. Saiful Islam ${ }^{1,2 *}$, Md. Estiar Rahman', Rajon Banik ${ }^{1}$, Md. Galib Ishraq Emran ${ }^{3}$, Noshin Saiara $^{4}$, Sahadat Hossain ${ }^{*}$, M. Tasdik Hasan ${ }^{5}$, Md. Tajuddin Sikder ${ }^{1}$, Lee Smith ${ }^{6}$, Marc N. Potenza ${ }^{7,8,9,10 *}$

$7{ }^{1}$ Department of Public Health and Informatics, Jahangirnagar University, Savar, Dhaka-1342,

8 Bangladesh

$9 \quad{ }^{2}$ Youth Research Association, Savar, Dhaka-1342, Bangladesh

$10{ }^{3}$ Department of Environmental Sciences, Jahangirnagar University, Savar, Dhaka-1342,

11 Bangladesh

$12{ }^{4}$ Department of Biotechnology and Genetic Engineering, Jahangirnagar University, Savar,

13 Dhaka-1342, Bangladesh

$14{ }^{5}$ Department of Primary Care \& Mental Health, University of Liverpool, UK

$15{ }^{6}$ The Cambridge Centre for Sport and Exercise Sciences, Anglia Ruskin University, 16 Cambridge, UK, CB1 1PT

$17{ }^{7}$ Department of Psychiatry and Child Study Center, Yale School of Medicine, New Haven, 18 Connecticut, USA

$19{ }^{8}$ Connecticut Mental Health Center, New Haven, Connecticut, USA

$20{ }^{9}$ Connecticut Council on Problem Gambling, Wethersfield, Connecticut, USA

$21{ }^{10}$ Department of Neuroscience, Yale University, New Haven, Connecticut, USA

$22 *$ Correspondence:

Md. Saiful Islam

24 islam.msaiful@outlook.com or saiful@phiju.edu.bd

25 Sahadat Hossain

26 sahadat.hossain@juniv.edu

27 Marc N. Potenza

28 marc.potenza@yale.edu

29 Keywords: depression: PTSD; COVID-19 pandemic; poverty; Bangladesh; sleep 


\section{$31 \quad$ ABSTRACT}

32 Background: The COVID-19 pandemic has impacted the physical, mental and financial health 33 of many individuals. How substantially marginalized groups like impoverished urban-dwelling 34 individuals are specifically impacted during this pandemic is poorly understood. The present study aimed to investigate correlates of financial concerns and symptoms of depression and posttraumatic stress disorder (PTSD) during the COVID-19 pandemic among impoverished urban-dwelling individuals residing in Dhaka, Bangladesh.

Methods: A cross-sectional survey was conducted between August and September 2020 using face-to-face interviews in six disadvantaged neighborhoods ("slums") in Dhaka. Individuals were interviewed using a structured questionnaire consisting of questions assessing sociodemographics, lifestyle, financial well-being relating to the COVID-19 pandemic, depression, and PTSD.

Results: Four-hundred-and-thirty-five individuals (male $=54.7 \%$; mean age $=45.0 \pm 12.0$ years; age range $=18-85$ years) participated. Most $(96.3 \%)$ reported that their household income decreased due to the COVID-19 pandemic. Factors associated with decreased household incomes included female gender, primary education, jobless, food scarcity and depression. Depression symptoms were linked to female gender, being jobless, being divorced, living in a joint family, excessive sleep and smoking. Low incomes, excessive sleep, joblessness and food scarcity were positively associated with PTSD symptoms. In contrast, less sleep appeared protective against PTSD.

Conclusions: Public health initiatives, in particular mental health services, should be introduced to mitigate against potential financial and psychological effects of the pandemic on impoverished urban-dwelling individuals in Bangladesh.

54 Keywords: depression: PTSD; COVID-19 pandemic; poverty; Bangladesh; sleep 


\section{INTRODUCTION}

The outbreak of the 2019 novel coronavirus (SARS-CoV-2) emerged in China at the end of 2019, which rapidly spread globally (Wang et al., 2020a; Xiang et al., 2020). COVID19 is considered a new public health crisis and on March 11,2020, it was declared a pandemic by the World Health Organization (WHO) (Cucinotta and Vanelli, 2020). In Bangladesh, the first case of COVID-19 was officially recorded on March 8, 2020 (Banik et al., 2020a; Ferdous et al., 2020), and since then the total number of confirmed cases has increased swiftly: approximately 404,760 cases have been confirmed with a death toll of 5,886 as of October 30, 2020 (Institute of Epidemiology Disease Control and Research, 2020). To deal with the pandemic, the governments of most countries have taken unprecedented preventative measures, including nationwide lockdowns, spatial distancing, business and work limitations and other actions (Anderson et al., 2020; Brooks et al., 2020).

The government of Bangladesh declared nationwide restrictions on public activities and movement across the country in March, 2020, in order to limit the spread of COVID-19 (Islam et al., 2020c; The Daily Star, 2020). While these pandemic-related constraints are critical for preventing COVID-19, they have also negatively impacted occupational opportunities, increased insecurity and generated financial challenges (Bhuiyan et al., 2020; Galicki, 2020). This has consequently influenced psychological health (Brooks et al., 2020; Wang et al., 2020 b), with an extensive range of psychological concerns relating to depression, anxiety, anger, loneliness and posttraumatic stress implicated (Islam et al., 2020e, 2020d; Xiao, 2020; Zandifar and Badrfam, 2020).

The COVID-19 has impacted individuals globally, and potentially especially impoverished urban-dwelling individuals living within congested environments and with limited resources. Currently, Dhaka (where the present study was conducted), the capital city of Bangladesh, has more than 3,300 disadvantaged neighborhoods ("slums") that house around 646,000 people, mostly comprised of poor day laborers and rickshaw drivers (The Daily Star, 2019; Kamruzzaman, 2020). These blighted areas are densely populated; approximately 75 percent of households live in one room (Bangladesh Bureau of Statistics (BBS) and UNICEF Bangladesh, 2014). In these areas of Bangladesh, population density is very high, amounting to 205,415 individuals $/ \mathrm{km}^{2}$ (United Nations, 2015; Islam and Kibria, 2020). About $37 \%$ of disadvanteaged households in urban areas have 26-50 square feet per person (Centre for Urban Studies (CUS) et al., 2006). In such circumstances, the impoverished urban residents in Dhaka often find themselves in particularly vulnerable conditions (Banik et al., 2020b), owing to experiencing even lower levels of income than usual and thus higher levels of financial uncertainty (Bhuiyan et al., 2020). Indeed, a recent report indicated extreme economic fallout due to the COVID-19 crisis among impoverished urban residents in Bangladesh with a reduction in per capita income by $82 \%$ from 108 Bangladeshi Taka (BDT) (\$1.30) in February, 2020, to 27 BDT (\$0.32) during the survey week in early April, 2020 (Kamruzzaman, 2020). Therefore, these individuals may be particularly vulnerable to psychological concerns due to extreme levels of financial insecurity exacerbated by the COVID-19 pandemic. A recent study found that the most vulnerable and poorest groups in Bangladesh will likely experience socioeconomic crises and substantial mental stress due to the COVID-19 pandemic (BodrudDoza et al., 2020; Shammi et al., 2020). Evidence from previous studies also found that the overall negative impact of COVID-19 on the economy, daily life and social activity was associated with greater psychological difficulties (Cao et al., 2020; Zhang and Ma, 2020). Several studies from Bangladesh and China during the initial phases of the COVID-19 pandemic revealed associations between COVID-19 experiences and anxiety, depression, and 
posttraumatic stress (Boyraz and Legros, 2020; Cao et al., 2020; Islam et al., 2020f; Liang et al., 2020; Wang et al., 2020b; Zhang and Ma, 2020).

Thus, there is an urgent need to understand the possible psychological issues that are faced by impoverished urban residents during this pandemic. However, to the best of our knowledge, no prior study has investigated psychological measures during the COVID-19 pandemic among impoverished urban residents in Bangladesh. Consequently, the current study aimed to explore the correlates of financial poverty and symptoms of depression and posttraumatic stress disorder (PTSD) during the COVID-19 outbreak among impoverished urban residents of Dhaka, Bangladesh.

\section{MATERIALS AND METHODS}

\subsection{Study design and setting}

The present study used a cross-sectional and interview-based survey of impoverished urban residents in Dhaka. The survey was conducted using a structured questionnaire between August and September 2020. The survey included 6 disadvantaged neighborhoods (Aziz Shaheber Bosti Bari, Balur Maath Songlongno Bosti, Fighter Bosti, Khurshid Bari Bosti, Pinur Bosti, and Shorgochera Bosti) located in Dhaka, Bangladesh.

\subsection{Study procedure}

All procedures of the present study were conducted in accordance with ethical principles of human investigations (i.e., Helsinki Declaration) and with the guideline of Institutional research ethics. After obtaining the formal ethics approval and the necessary coordination of the ethical review board of Jahangirnagar University [Ref. No: BBEC, JU/ M 2020/COVID-19/(8)5], the present study was initiated. A Bangla questionnaire incorporating informed consent along with all measures was employed when conducting face-to-face interviews to gather information from participants while maintaining proper precautions and spatial distancing amid the COVID-19 pandemic. Considering the health risks associated with the ongoing pandemic, precautionary safety measures were taken during data collection. Participants were informed about the procedures and purpose of the study and the confidentiality of information provided. All data were collected anonymously and analyzed using a pre-determined coding system.

\subsection{Sampling method}

The sample size was calculated using the following equation:

$$
n=\frac{z^{2} p q}{d^{2}} ; n=\frac{1.96^{2} \times 0.5 \times(1-0.5)}{0.05^{2}}=384.16 \approx 384 \begin{aligned}
& \text { Here }, \\
& z=1.96(95 \% \text { confidence level }) \\
& z=\text { prevalence estimate }(0.5) \\
& q=(1-p) \\
& d=\text { precision limit or proportion of sampling error }(0.05)
\end{aligned}
$$

There is no prior similar study focusing on the study group during the COVID-19 pandemic. Thus, we hypothesized that psychological problems would be approximately $50 \%$ among impoverished urban residents during the pandemic. Assuming a 10\% non-response rate, a total of $423.5 \approx 424$ participants was estimated. However, 435 participants were recruited to ensure adequate power for the study (see Figure 1). 
The inclusion criteria for participants were (i) being aged $\geq 18$ years, (ii) being impoverished urban residents, and (iii) willingness to enroll in the survey. Exclusion criteria were being $<18$ years old and not being able to provide consent. After obtaining informed consent, 439 participants were interviewed using a convenience sampling approach. At the data quality checking stage, 4 participants with incomplete surveys were removed, and 435 participants were included in the final analysis.

\subsection{Measures}

The questionnaire included informed consent and questions assessing sociodemographics, lifestyle, financial status and COVID-19-related impacts, depression and PTSD.

\subsubsection{Socio-demographics and lifestyle-related measure}

During the interview, data were collected on gender (male vs. female), age, marital status (unmarried/married/divorced/widowed), education (no formal education, primary level [1-5 grades], and secondary level [6-10 grades] or higher), occupation, family type (nuclear vs. joint), and monthly family income. Age was subsequently categorized into two groups: 18-40 years and $>40$ years; and monthly family income was categorized into three groups: $<5,000$ Bangladeshi Taka [BDT], 6,000-15,000 BDT and >15,000 BDT.

In addition, numbers of average sleep hours and smoking status were assessed during the interview. Numbers of average sleep hours were classified as normal (7-9 hours), less than normal $(<7 \mathrm{~h})$, or more than normal $(>9 \mathrm{~h})$ based on previous reports (Hirshkowitz et al., 2015; Chen et al., 2020; Islam et al., 2020a).

\subsubsection{Financial impact measure}

The financial impact of COVID-19 was assessed by asking, "How has your family's monthly income changed due to the impact of COVID-19?". There were three possible responses (i) decreased; (ii) increased; (iii) unchanged, as previously reported (Tran et al., 2020). Subsequently, responses were as "no income change" if they responded to their income "unchanged" relative to the impact of COVID-19. No participants reported their income "increased" due to the impact of the COVID-19 pandemic so the remainder reported decreased incomes. Two additional 'yes/no' questions were asked during the survey concerning job loss and food scarcity in their families due to COVID-19.

\subsubsection{Patient Health Questionnaire (PHQ-9)}

The PHQ-9 is a unidimensional psychometric instrument developed by Spitzer et al. (1999) for assessing depressive disorder. It is a psychometrically sound and robust screening tool used globally in epidemiological surveys. The scale contains nine questions regarding problems related to depressive symptoms over the past two weeks (e.g., "Trouble falling or staying asleep, or sleeping too much") with a four-point Likert scale ranging from 0 (Not at all) to 3 (Nearly every day). The present study utilized the Bangla version of the PHQ-9 (Chowdhury et al., 2004) to assess participants' depressive symptomatology as previously in Bangla samples (Islam et al., 2020b; Moonajilin et al., 2020; Rahman et al., 2020). The total score ranged from 0 to 27 with higher scores reflecting greater severity. In the present study, the reliability coefficient Cronbach's $\alpha$ of the PHQ-9 scale was 0.83 .

\subsubsection{National Stressful Events Survey for PTSD-Short Scale (NSESSS-PTSD)}


The NSESSS-PTSD is a brief, easy to use, psychometrically sound and robust instrument for assessing PTSD, developed by LeBeau et al. (2014) and which supports DSM5 diagnostic criteria. This scale consists of nine-item questions regarding problems related to PTSD symptoms over the last week (i.e., "Feeling very emotionally upset when something reminded you of a stressful experience") with a five-point Likert scale ranging from 0 (Not at all) to 4 (Extremely). The present study used the Bangla version of the NSESSS-PTSD to assess participants' PTSD. The NSESSS-PTSD was translated following back translation, the most widely used standardized translation, as proposed by Beaton et al. (2000). The total score ranged from 0 to 36 with higher scores reflecting more severe PTSD. In the present study, the internal consistency for the NSESSS-PTSD (Cronbach's $\alpha=0.70$ ) was acceptable (Taber, 2018).

\subsection{Statistical analyses}

Analyses were performed using three statistical software packages (Microsoft Excel 2019, IBM SPSS Statistics version 25, and STATA version 13). Microsoft Excel was used to perform data cleaning, coding, editing and sorting. Then an excel file including all variables was imported into SPSS software. With regard to categorical variables, frequencies and percentages were reported; means and standard deviations were presented for continuous data. In addition, some first-order analyses (e.g., Chi-square tests, Fisher's exact tests) were performed using SPSS. Finally, the multivariate linear regression model was investigated using STATA to explore the correlates of depression and PTSD symptomatology. A $p$-value less than 0.05 was considered as statistically significant.

\section{RESULTS}

\subsection{General characteristics of participants}

Participants $(\mathrm{n}=435)$ had a mean age of 45.0 years $(\mathrm{SD}=12)$ and ranged from 18 to 85 years. Regarding participants, $54.7 \%$ were male and most were married (87.4\%; see Table 1 ). Most participants had a primary level of education (grades $1-5 ; 74.3 \%$ ), had monthly family income $\leq 10,000$ BDT (55.9\%), and belonged to a nuclear family (89.0\%; Table 1$)$. Many indicated that they kept small shops (24.8\%). Most reported that they slept in a normal range (7-9 hours/day; 66.7\%), and a sizeable minority smoked cigarettes $(23.2 \%)$. A vast majority reported that they had lost their jobs due to the impact of the COVID-19 pandemic (95.6\%). Likewise, $98.9 \%$ reported they had suffered from food scarcity due to the COVID-19 pandemic.

\subsection{Financial concerns and their correlates}

Most participants reported their household income was decreased due to the impact of COVID-19 (96.3\%). Household income decreases due to the impact of COVID-19 were related to (i) being female vs. male $(98.5 \%$ vs. $94.5 \%, p=0.039)$, (ii) having had primary vs. no formal education ( $97.8 \%$ vs. $91.1 \%, p=0.010)$, (iii) having had lost jobs vs. not $(97.0 \%$ vs. $40.0 \%, p<0.001)$, (iv) having had experienced food scarcity due to COVID-19 vs. not $(97.0 \%$ vs. $40.0 \%, p<0.001)$, and (v) having higher vs. lower depression scores $(7.2 \pm 4.4$ vs. 5.0 \pm 5.0 , $p=0.05$ ).

\subsection{Associations with depression and PTSD}


The mean scores of depression and PTSD were 7.1 \pm 4.4 (out of 27) and 15.1 \pm 3.4 (out of 36), respectively. Features related to depression and PTSD are presented in Figure 2. Of note, depression and PTSD were significantly and positively correlated with each other (Person $r=0.34 ; p<0.001$ ).

Table 2 summarizes a multivariate regression analysis statistically predicting depression and PTSD. In Model 1, all examined variables were entered together to examine associations with depression symptoms. Higher depression scores were positively and significantly associated with female gender $(\beta=0.19 ; p<0.05)$, joblessness due to the COVID19 pandemic $(\beta=0.11 ; p<0.05)$, being divorced $(\beta=0.20 ; p<0.001)$, living in joint family $(\beta=0.13 ; p<0.01)$, excessive sleep ( $>9$ hours/day) $(\beta=0.09 ; p<0.05)$, and smoking $(\beta=0.14$; $p<0.01)$. The regression Model 1 predicted overall $17 \%$ of the variance in depression scores $\left(F_{(20,414)}=5.53, p<0.001\right)$.

Next, all measures were entered together to examine associations with PTSD symptoms in Model 2. Higher PTSD scores were positively correlated with having monthly income $\leq 10,000$ BDT $(\beta=0.17 ; p<0.01)$, excessive sleep ( $>9$ hours $/$ day) $(\beta=0.11 ; p<0.05)$, being jobless due to the COVID-19 pandemic $(\beta=0.13 ; p<0.05)$, and experiencing food scarcity due to the COVID-19 pandemic $(\beta=0.14 ; p<0.01)$; less sleep ( $<7$ hours/day) was negatively associated with PTSD scores $(\beta=-0.11 ; p<0.05)$. The regression Model 2 predicted overall $10 \%$ of the variance in PTSD scores $\left(F_{(20,414)}=3.33, p<0.001\right)$.

\section{DISCUSSION}

The COVID-19 pandemic has exerted psychological and financial impacts on many people (Banna et al., 2020; Bodrud-Doza et al., 2020; Islam et al., 2020d; Zubayer et al., 2020). Among urban dwellers worldwide, the pandemic has had a serious impact on impoverished urban residents compared to others, especially those living in low- and middle-income countries (Tampe, 2020). The present study investigated financial hardships and depression and PTSD symptoms among impoverished urban residents in Dhaka, Bangladesh during the COVID-19 pandemic. Notably, the vast majority of individuals (>95\%) experienced decreased household incomes, job losses and food insecurity during the COVID-19 pandemic. As there have been no prior studies in Bangladesh investigating financial hardships along with mental health among this marginalized group, the present findings have been placed in the context of findings from prior studies undertaken in different regions and involving different populations.

The COVID-19 pandemic has had a major impact on the country's economy and on individuals, apart from its impacts on the national health situation (Bodrud-Doza et al., 2020). Due to the current pandemic, many individuals or families have lost their sources of income (The World Bank, 2020). In the present study, 96.3\% of respondents reported a decrease in their household income due to the impact of the COVID-19 pandemic. This rate is higher than those in Vietnam (66.9\%) (Tran et al., 2020) and India (45.6\%) (Keelery, 2020). The disparity could be attributable to differences in economic structures and major markets between countries. The economy of Bangladesh has heavily relied on ready-made garments and foreign remittance, affected badly by the COVID-19 pandemic (Amit, 2020). In this study, the decreased household income was associated with being female, having a primary education level, having lost jobs, having experienced food scarcity and exhibiting more symptoms of depression. Household income being reduced more among females than males due to the impact of the COVID-19 pandemic resonates with prior findings (Rudkin, 1993). A primary education level was associated with decreased household income during the COVID-19 pandemic, possibly owing to these individuals being in unskilled and "disposable" 
employment. In addition, decreased household income during the COVID-19 pandemic was linked to losing jobs, experiencing food scarcity and depression. Several of these factors may relate to periods of lockdown or closure of businesses following the requirement of strict spatial distancing in Bangladesh.

In the present study, the regression analysis exhibited that being female, experiencing joblessness due to the COVID-19 pandemic, being divorced, living in a joint family, sleeping excessively ( $>9$ hours/day), and smoking were associated with higher depression scores. Females reported higher depression scores than males. This finding is consistent with previous studies (Van Droogenbroeck et al., 2018; Hossain et al., 2019) that showed that females were more likely to be depressed than males. Females may experience increased emotional vulnerability and suffer more from stressors related to negative psychological effects, such as the death of friends or family, and these factors may hold relevance during a pandemic (Matheson et al., 2014; Van Droogenbroeck et al., 2018).

Participants with joblessness attributable to the COVID-19 pandemic experienced more depression, consistent with prior studies (Mandal et al., 2011; Stolove et al., 2017). The COVID-19 pandemic has generated job loss/displacement, resulting in decreased incomes (Tran et al., 2020), and these events may contribute to depression.

Being divorced was associated with depression in the present study, consistent with previous reports (Sbarra et al., 2014). This association may reflect loneliness, isolation, and other social problems that may be experienced in a more solitary fashion when divorced and may be particularly impactful during the pandemic (Saltzman et al., 2020). The present study also observed an association between depression and living in joint families, supporting prior findings (Mishra et al., 2018); however, the finding is distinct from those in a prior Bangladeshi study (Islam et al., 2020f) reporting no relationship between family type and depression. In contrast, prior data have linked residing in nuclear families to depression (Taqui et al., 2007). These differences may reflect certain circumstances relating to impoverished living settings during a pandemic that speculatively may include financial hardships related to greater monthly household costs, job displacements, food scarcity or other factors. These considerations warrant further investigation.

Excessive sleep ( $>9$ hours/day) was associated with depression. This finding aligns with a prior Bangladeshi longitudinal study (Hossain et al., 2019) and reviewed findings (Lovato and Gradisar, 2014) but appears to contrast with prior Bangladeshi reports (Anjum et al., 2019; Islam et al., 2020a) that observed no association between sleeping hours and depression. The extent to which the findings might relate to longer sleep of poorer quality given crowded living situations or other factors warrants additional study. The present findings also linked smoking to depression, consistent with prior reports in Bangladesh (Islam et al., 2020f; Tasnim et al., 2020) and global findings from 48 low- and middle-income countries (Stubbs et al., 2018) and a systematic review (Fluharty et al., 2017).

In regression analyses, higher PTSD scores were associated with having monthly incomes $\leq 10,000 \mathrm{BDT}$, excessive sleep ( $>9$ hours/day), having experienced job loss due to the COVID-19 pandemic and having experienced food scarcity due to the COVID-19 pandemic. This study revealed no gender difference relating to PTSD symptoms, which differs from a recent study from China during the COVID-19 pandemic that reported higher PTSD symptomatology among females compared to males (Liu et al., 2020). The extent to which this difference may reflect cultural differences or distinct populations warrants additional study. 
Lower income $(\leq 10,000$ BDT $\approx \leq 118$ US\$ per month) and sleep disturbances reports (Maher et al., 2006; Parto et al., 2011). A scoping review also concluded that individuals who suffer from PTSD have sleep disturbances (Magnavita and Garbarino, 2017). The seemingly protective effect of less sleep warrants further investigation.

The present study also indicated that job loss and food insecurity due to the COVID-19 pandemic were associated with more severe PTSD symptomatology. Spatial distancing and lockdown measures in conjunction with living in close quarters are factors that speculatively may generate PTSD symptoms. Other factors, including disruptions to everyday life and routines, financial losses, job losses, and lack of social support, may also contribute to PTSD symptoms (Boyraz and Legros, 2020; Islam et al., 2020e). Low-income communities may be at particular risk of developing PTSD as impoverished urban residents may experience more trauma than some other groups living in more well-developed areas (Boyraz and Legros, 2020). A dense population, congested living accommodations and lower incomes warrant consideration in the development and addressing of PTSD symptomatology. PTSD develops when symptoms from a psychological trauma disrupt daily functioning and last for over a month. PTSD symptoms may persist for decades if not treated (Bo et al., 2020). Therefore, the present study suggests the need for effective interventions, including outreach efforts, behavioral and psychopharmacological treatments, and addressing of traumatic living situations and life experiences (Horesh and Brown, 2020).

\subsection{Limitations}

There are study limitations that warrant discussion. This study was cross-sectional and thus unable to make causal inferences. Future longitudinal studies are needed. The findings may not generalize to other impoverished urban residents beyond Dhaka, Bangladesh. Future larger-scale studies involving other jurisdictions are warranted. The study gathered a limited number of COVID-19-related assessments. Future studies should examine additional relevant COVID-19-related domains using validated questions. Further, as decreases in household income were highly prevalent, ceiling effects may have influenced findings.

\section{CONCLUSIONS}

Marginalized communities like impoverished urban residents have been greatly impacted amid the COVID-19 pandemic with their dense population, congested accommodations and low incomes. Most impoverished urban residents reported decreased household incomes due to the COVID-19 pandemic. This study also assessed psychological distress (i.e., depression and PSTD) among participants. There is a crucial need for a thorough evaluation of the effects of the COVID-19 pandemic on various groups over the next decade, which will inform the government of the need to introduce effective policies to ease the economic and psychological pain of vulnerable communities. Public health initiatives, in particular mental health services, should be introduced to mitigate the psychological effects of the pandemic on impoverished urban residents and other vulnerable populations.

\section{CONFLICT OF INTEREST}

The authors report no conflicts of interest with the content of this manuscript. Dr. Potenza has the following financial disclosures. He has consulted for and advised Opiant Pharmaceuticals, Idorsia Pharmaceuticals, AXA, Game Day Data, and the Addiction Policy Forum; has received research support from the Mohegan Sun Casino, the Connecticut Council 
on Problem Gambling, and the National Center for Responsible Gaming; has participated in surveys, mailings or telephone consultations related to drug addiction, impulse control disorders or other health topics; and has consulted for law offices and gambling entities on issues related to impulse control or addictive disorders.

The other authors declare that they do not have any financial or other relations with companies, trade associations, unions or groups.

All authors declare the absence of relationships with entities that may gain or lose financially from the results or conclusions in the study.

\section{AUTHOR CONTRIBUTIONS}

Conceptualization: Md. Saiful Islam, Md. Galib Ishraq Emran, Sahadat Hossain; Methodology: Md. Saiful Islam; Formal analysis: Md. Saiful Islam; Investigation: Md. Saiful Islam, Md. Galib Ishraq Emran, Sahadat Hossain; Resources: Md. Galib Ishraq Emran; Supervision: Sahadat Hossain; Writing - original draft preparation: Md. Saiful Islam, Md. Estiar Rahman, Rajon Banik; Writing - review and editing: Noshin Saiara, Sahadat Hossain, M. Tasdik Hasan, Md. Tajuddin Sikder, Lee Smith, Marc N. Potenza. All authors read and approved the final manuscript.

\section{FUNDING}

The authors did not receive any grants or remunerations from either public or private organizations or other funding agencies.

\section{ACKNOWLEDGEMENTS}

The authors would like to express the most profound gratitude to all of the respondents who participated in this study voluntarily and spontaneously. 


\section{References}

Amit, S. (2020). Coronavirus and impact on the Bangladesh economy: assessing the damage of the black swan of 2020. Asia-Pacific J. 18, 9.

Anderson, R. M., Heesterbeek, H., Klinkenberg, D., and Hollingsworth, T. D. (2020). How will country-based mitigation measures influence the course of the COVID-19 epidemic? Lancet 395, 931-934. doi:10.1016/S0140-6736(20)30567-5.

Anjum, A., Hossain, S., Sikder, T., Uddin, M. E., and Rahim, D. A. (2019). Investigating the prevalence of and factors associated with depressive symptoms among urban and semiurban school adolescents in Bangladesh: a pilot study. Int. Health. doi:10.1093/inthealth/ihz092.

Bangladesh Bureau of Statistics (BBS), and UNICEF Bangladesh (2014). Bangladesh Multiple Indicator Cluster Survey 2012-2013, ProgotirPathey: Final Report. Dhaka.

Banik, R., Rahman, M., Sikder, D. M., Rahman, Q., and Pranta, M. (2020a). Investigating knowledge, attitudes, and practices related to COVID-19 outbreak among Bangladeshi young adults: A web-based cross-sectional analysis. Res. Sq. doi:10.21203/rs.3.rs37946/v2.

Banik, R., Rahman, M., Sikder, T., and Gozal, D. (2020b). SARS-CoV-2 pandemic: an emerging public health concern for the poorest in Bangladesh. Public Heal. Pract., 100024. doi:10.1016/j.puhip.2020.100024.

Banna, M. H. Al, Sayeed, A., Kundu, S., Christopher, E., Hasan, M. T., Begum, M. R., et al. (2020). The impact of the COVID-19 pandemic on the mental health of the adult population in Bangladesh: a nationwide cross-sectional study. Int. J. Environ. Health Res., 1-12. doi:10.1080/09603123.2020.1802409.

Beaton, D. E., Bombardier, C., Guillemin, F., and Ferraz, M. B. (2000). Guidelines for the process of cross-cultural adaptation of self-report measures. Spine (Phila. Pa. 1976). 25, 3186-3191. doi:10.1097/00007632-200012150-00014.

Bhuiyan, A. K. M. I., Sakib, N., Pakpour, A. H., Griffiths, M. D., and Mamun, M. A. (2020). COVID-19-related suicides in bangladesh due to lockdown and economic factors: case study evidence from media reports. Int. J. Ment. Health Addict., 1-6. doi:10.1007/s11469-020-00307-y.

Bo, H.-X., Li, W., Yang, Y., Wang, Y., Zhang, Q., Cheung, T., et al. (2020). Posttraumatic stress symptoms and attitude toward crisis mental health services among clinically stable patients with COVID-19 in China. Psychol. Med., 1-2. doi:10.1017/S0033291720000999.

Bodrud-Doza, M., Shammi, M., Bahlman, L., Islam, A. R. M. T., and Rahman, M. M. (2020). Psychosocial and socio-economic crisis in Bangladesh due to COVID-19 pandemic: a perception-based assessment. Front. public Heal. 8, 341. doi:10.3389/fpubh.2020.00341. 
Boyraz, G., and Legros, D. N. (2020). Coronavirus disease (COVID-19) and traumatic stress: probable risk factors and correlates of posttraumatic stress disorder. J. Loss Trauma, 120. doi:10.1080/15325024.2020.1763556.

Brooks, S. K., Webster, R. K., Smith, L. E., Woodland, L., Wessely, S., Greenberg, N., et al. (2020). The psychological impact of quarantine and how to reduce it: rapid review of the evidence. Lancet 395, 912-920. doi:10.1016/S0140-6736(20)30460-8.

Cao, W., Fang, Z., Hou, G., Han, M., Xu, X., Dong, J., et al. (2020). The psychological impact of the COVID-19 epidemic on college students in China. Psychiatry Res. 287, 112934. doi:10.1016/j.psychres.2020.112934.

Centre for Urban Studies (CUS), National Institute of Population Research and Training (NIPORT), and MEASURE Evaluation (2006). "Slums of Urban Bangladesh: Mapping and Census, 2005," in (Dhaka, Bangladesh and Chappell Hill, USA).

Chen, X., Wang, S.-B., Li, X.-L., Huang, Z.-H., Tan, W.-Y., Lin, H.-C., et al. (2020). Relationship between sleep duration and sociodemographic characteristics, mental health and chronic diseases in individuals aged from 18 to 85 years old in Guangdong province in China: a population-based cross-sectional study. BMC Psychiatry 20, 455. doi:10.1186/s12888-020-02866-9.

Chowdhury, A., Ghosh, S., and Sanyal, D. (2004). Bengali adaptation of Brief Patient Health Questionnaire for screening depression at primary care. J. Indian Med. Assoc. 102, 544 547.

Cucinotta, D., and Vanelli, M. (2020). WHO declares COVID-19 a pandemic. Acta biomedica Atenei Parm. 91, 157-160. doi:10.23750/abm.v91i1.9397.

Ferdous, M. Z., Islam, M. S., Sikder, M. T., Mosaddek, A. S. M., Zegarra-Valdivia, J. A., and Gozal, D. (2020). Knowledge, attitude, and practice regarding COVID-19 outbreak in Bangladesh: an online-based cross-sectional study. PLoS One 15, e0239254. doi:10.1371/journal.pone.0239254.

Fluharty, M., Taylor, A. E., Grabski, M., and Munafò, M. R. (2017). The association of cigarette smoking with depression and anxiety: a systematic review. Nicotine Tob. Res. 19, 3-13. doi:10.1093/ntr/ntw140.

Galicki, C. (2020). Impact of COVID-19 on financial wellbeing: key findings from a national survey. New Zealand: Commission for Financial Capability Available at: https://apo.org.au/sites/default/files/resource-files/2020-05/apo-nid305917.pdf.

Hirshkowitz, M., Whiton, K., Albert, S. M., Alessi, C., Bruni, O., DonCarlos, L., et al. (2015). National Sleep Foundation's updated sleep duration recommendations: final report. Sleep Heal. 1, 233-243. doi:10.1016/j.sleh.2015.10.004.

Horesh, D., and Brown, A. D. (2020). Traumatic stress in the age of COVID-19: a call to close critical gaps and adapt to new realities. Psychol. Trauma 12, 331-335. doi: $10.1037 /$ tra0000592. 
Hossain, S., Anjum, A., Uddin, M. E., Rahman, M. A., and Hossain, M. F. (2019). Impacts of socio-cultural environment and lifestyle factors on the psychological health of university students in Bangladesh: A longitudinal study. J. Affect. Disord. 256, 393-403. doi:10.1016/j.jad.2019.06.001.

Institute of Epidemiology Disease Control and Research (2020). Covid-19 status for Bangladesh. Available at: http://old.iedcr.gov.bd/ [Accessed June 28, 2020].

Islam, M. S., Akter, R., Sikder, M. T., and Griffiths, M. D. (2020a). Weight-related status and associated predictors with psychological well-being among first-year university students in Bangladesh: a pilot study. Int. J. Ment. Health Addict. doi:10.1007/s11469-02000243-X.

Islam, M. S., Akter, R., Sikder, T., and Griffiths, M. D. (2020b). Prevalence and factors associated with depression and anxiety among first-year university students in Bangladesh: a cross-sectional study. Int. J. Ment. Health Addict. doi:10.1007/s11469020-00242-y.

Islam, M. S., Emran, G. I., Rahman, E., Banik, R., Sikder, T., Smith, L., et al. (2020c). Knowledge, attitudes and practices associated with the COVID-19 among slum dwellers resided in Dhaka City: a Bangladeshi interview-based survey. J. Public Health (Bangkok). doi:10.1093/pubmed/fdaa182.

Islam, M. S., Ferdous, M. Z., and Potenza, M. N. (2020d). Panic and generalized anxiety during the COVID-19 pandemic among Bangladeshi people: an online pilot survey early in the outbreak. J. Affect. Disord. 276, 30-37. doi:10.1016/j.jad.2020.06.049.

Islam, M. S., Potenza, M. N., and Van Os, J. (2020e). Posttraumatic stress disorder during the COVID-19 pandemic: upcoming challenges in Bangladesh and preventive strategies. Int. J. Soc. Psychiatry. doi:10.1177/0020764020954469.

Islam, M. S., Sujan, M. S. H., Tasnim, R., Sikder, M. T., Potenza, M. N., and van Os, J. (2020f). Psychological responses during the COVID-19 outbreak among university students in Bangladesh. PLoS One 15, e0245083. doi:10.1371/journal.pone.0245083.

Islam, T., and Kibria, M. G. (2020). Challenges to the prevention of COVID-19 spread in slums of Bangladesh. J. Public Health (Bangkok). 42, 637-638. doi:10.1093/pubmed/fdaa088.

Kamruzzaman, M. (2020). Coronavirus: poor income drops $80 \%$ in Bangladesh. Anadolu Agency. Available at: https://www.aa.com.tr/en/asia-pacific/coronavirus-poor-incomedrops-80-inbangladesh/1808837?fbclid=IwAR1aIus2Ie_iBXA6SM1B2o0vn4u8vkPw7BhTHCmpu GW3JLS9I_mtuZTG85k [Accessed October 26, 2020].

Keelery, S. (2020). Impact on household income due to the coronavirus (COVID-19) in India from February to April 2020. Available at: https://www.statista.com/statistics/1111510/india-coronavirus-impact-on-householdincome/\#: :text=Household income in India was,45.7 percent in mid April. [Accessed October 20, 2020]. 
LeBeau, R., Mischel, E., Resnick, H., Kilpatrick, D., Friedman, M., and Craske, M. (2014). Dimensional assessment of posttraumatic stress disorder in DSM-5. Psychiatry Res. 218, 143-147. doi:10.1016/j.psychres.2014.03.032.

Liang, L., Gao, T., Ren, H., Cao, R., Qin, Z., Hu, Y., et al. (2020). Post-traumatic stress disorder and psychological distress in Chinese youths following the COVID-19 emergency. J. Health Psychol. 25, 1164-1175. doi:10.1177/1359105320937057.

Liu, N., Zhang, F., Wei, C., Jia, Y., Shang, Z., Sun, L., et al. (2020). Prevalence and predictors of PTSS during COVID-19 outbreak in China hardest-hit areas: gender differences matter. Psychiatry Res. 287, 112921. doi:10.1016/j.psychres.2020.112921.

Lovato, N., and Gradisar, M. (2014). A meta-analysis and model of the relationship between sleep and depression in adolescents: recommendations for future research and clinical practice. Sleep Med. Rev. 18, 521-529. doi:10.1016/j.smrv.2014.03.006.

Magnavita, N., and Garbarino, S. (2017). Sleep, health and wellness at work: a scoping review. Int. J. Environ. Res. Public Health 14, 1347.

Maher, M. J., Rego, S. A., and Asnis, G. M. (2006). Sleep disturbances in patients with posttraumatic stress disorder: epidemiology, impact and approaches to management. CNS Drugs 20, 567-590. doi:10.2165/00023210-200620070-00003.

Mandal, B., Ayyagari, P., and Gallo, W. T. (2011). Job loss and depression: the role of subjective expectations. Soc. Sci. Med. 72, 576-583. doi:10.1016/j.socscimed.2010.11.014.

Matheson, F. I., Smith, K. L. W., Moineddin, R., Dunn, J. R., and Glazier, R. H. (2014). Mental health status and gender as risk factors for onset of physical illness over 10 years. J. Epidemiol. Community Health 68, 64-70. doi:10.1136/jech-2013-202838.

Mishra, S. K., Srivastava, M., Tiwary, N. K., and Kumar, A. (2018). Prevalence of depression and anxiety among children in rural and suburban areas of Eastern Uttar Pradesh: a cross-sectional study. J. Fam. Med. Prim. care 7, 21-26. doi:10.4103/jfmpc.jfmpc_248_17.

Moonajilin, M. S., Rahman, M. E., and Islam, M. S. (2020). Relationship between overweight/obesity and mental health disorders among Bangladeshi adolescents: a crosssectional survey. Obes. Med. 18, 100216. doi:10.1016/j.obmed.2020.100216.

Parto, J. A., Evans, M. K., and Zonderman, A. B. (2011). Symptoms of posttraumatic stress disorder among urban residents. J. Nerv. Ment. Dis. 199, 436-439. doi:10.1097/NMD.0b013e3182214154.

Rahman, M. E., Islam, M. S., Mamun, M. A., Moonajilin, M. S., and Yi, S. (2020). Prevalence and factors associated with suicidal ideation among university students in Bangladesh. Arch. Suicide Res., 1-10. doi:10.1080/13811118.2020.1833800.

Rudkin, L. (1993). Gender differences in economic well-being among the elderly of java. Demography 30, 209-226. doi:10.2307/2061838. 
Saltzman, L. Y., Hansel, T. C., and Bordnick, P. S. (2020). Loneliness, isolation, and social support factors in post-COVID-19 mental health. Psychol. Trauma 12, S55-S57. doi: $10.1037 /$ tra0000703.

Sbarra, D. A., Emery, R. E., Beam, C. R., and Ocker, B. L. (2014). Marital dissolution and major depression in midlife: a propensity score analysis. Clin. Psychol. Sci. a J. Assoc. Psychol. Sci. 2, 249-257. doi:10.1177/2167702613498727.

Shammi, M., Bodrud-Doza, M., Towfiqul Islam, A. R. M., and Rahman, M. M. (2020). COVID-19 pandemic, socioeconomic crisis and human stress in resource-limited settings: a case from Bangladesh. Heliyon 6, e04063. doi:10.1016/j.heliyon.2020.e04063.

Spitzer, R. L., Kroenke, K., and Williams, J. B. (1999). Validation and utility of a self-report version of PRIME-MD: the PHQ primary care study. Primary Care Evaluation of Mental Disorders. Patient Health Questionnaire. JAMA 282, 1737-1744. doi:10.1001/jama.282.18.1737.

Stolove, C. A., Galatzer-Levy, I. R., and Bonanno, G. A. (2017). Emergence of depression following job loss prospectively predicts lower rates of reemployment. Psychiatry Res. 253, 79-83. doi:10.1016/j.psychres.2017.03.036.

Stubbs, B., Vancampfort, D., Firth, J., Solmi, M., Siddiqi, N., Smith, L., et al. (2018). Association between depression and smoking: a global perspective from 48 low- and middle-income countries. J. Psychiatr. Res. 103, 142-149. doi:10.1016/j.jpsychires.2018.05.018.

Taber, K. S. (2018). The use of Cronbach's alpha when developing and reporting research instruments in science education. Res. Sci. Educ. 48, 1273-1296.

Tampe, T. (2020). Potential impacts of COVID-19 in urban slums: addressing challenges to protect the world's most vulnerable. Cities Heal., 1-4. doi:10.1080/23748834.2020.1791443.

Taqui, A. M., Itrat, A., Qidwai, W., and Qadri, Z. (2007). Depression in the elderly: does family system play a role? a cross-sectional study. BMC Psychiatry 7, 57. doi:10.1186/1471-244X-7-57.

Tasnim, R., Sujan, M. S. H., Islam, M. S., Ritu, A. H., Siddique, M. A. Bin, Toma, T. Y., et al. (2020). Prevalence and correlates of anxiety and depression in frontline healthcare workers treating people with COVID-19 in Bangladesh. PsyArXiv. doi:10.31234/osf.io/3qg9p.

The Daily Star (2019). Over 6 lakh slum dwellers in Dhaka: Minister. Available at: https://www.thedailystar.net/city/6-lakh-slum-dwellers-in-dhaka-1757827 [Accessed September 2, 2020].

The Daily Star (2020). Coronavirus outbreak: Govt orders closure of public, private offices from March 26 to April 4. Available at: https://www.thedailystar.net/coronavirusdeadly-new-threat/news/govt-offices-closed-march-26-april-4-cabinet-secretary- 
1884730 [Accessed July 10, 2020].

The World Bank (2020). The global economic outlook during the COVID-19 pandemic: a changed world. Available at: https://www.worldbank.org/en/news/feature/2020/06/08/the-global-economic-outlookduring-the-covid-19-pandemic-a-changed-world [Accessed October 20, 2020].

Tran, B. X., Nguyen, H. T., Le, H. T., Latkin, C. A., Pham, H. Q., Vu, L. G., et al. (2020). Impact of COVID-19 on economic well-being and quality of life of the Vietnamese during the national social distancing. Front. Psychol. 11, 2289. doi:10.3389/fpsyg.2020.565153.

United Nations (2015). Millennium Development Goals Indicators. Available at: http://mdgs.un.org/unsd/mdg/default.aspx.

Van Droogenbroeck, F., Spruyt, B., and Keppens, G. (2018). Gender differences in mental health problems among adolescents and the role of social support: results from the Belgian health interview surveys 2008 and 2013. BMC Psychiatry 18, 6. doi:10.1186/s12888-018-1591-4.

Wang, C., Horby, P. W., Hayden, F. G., and Gao, G. F. (2020a). A novel coronavirus outbreak of global health concern. Lancet 395, 470-473. doi:10.1016/S01406736(20)30185-9.

Wang, C., Pan, R., Wan, X., Tan, Y., Xu, L., Ho, S. C., et al. (2020b). Immediate psychological responses and associated factors during the initial stage of the 2019 coronavirus disease (COVID-19) epidemic among the general population in China. Int. J. Environ. Res. Public Health 17. doi:10.3390/ijerph17051729.

Xiang, Y.-T., Yang, Y., Li, W., Zhang, L., Zhang, Q., Cheung, T., et al. (2020). Timely mental health care for the 2019 novel coronavirus outbreak is urgently needed. The lancet. Psychiatry 7, 228-229. doi:10.1016/S2215-0366(20)30046-8.

Xiao, C. (2020). A novel approach of consultation on 2019 novel coronavirus (COVID-19)related psychological and mental problems: structured letter therapy. Psychiatry Investig. 17, 175-176. doi:10.30773/pi.2020.0047.

Zandifar, A., and Badrfam, R. (2020). Iranian mental health during the COVID-19 epidemic. Asian J. Psychiatr. 51, 101990. doi:10.1016/j.ajp.2020.101990.

Zhang, Y., and Ma, Z. F. (2020). Impact of the COVID-19 pandemic on mental health and quality of life among local residents in Liaoning Province, China: a cross-sectional study. Int. J. Environ. Res. Public Health 17, 2381. doi:10.3390/ijerph17072381.

Zubayer, A. Al, Rahman, M. E., Islam, M. B., Babu, S. Z. D., Rahman, Q. M., Bhuiyan, M. R. A. M., et al. (2020). Psychological states of Bangladeshi people four months after the COVID-19 pandemic: an online survey. Heliyon 6, e05057. doi:10.1016/j.heliyon.2020.e05057. 
Table 1. Measures and their associations with household income decreases due to the impact of COVID-19

\begin{tabular}{|c|c|c|c|c|c|c|c|c|c|}
\hline \multirow{3}{*}{ Characteristics } & \multicolumn{4}{|c|}{ Household income changes due to COVID-19 } & \multirow{2}{*}{\multicolumn{2}{|c|}{ Total }} & \multirow{3}{*}{$\chi^{2}$} & \multirow{3}{*}{ df } & \multirow{3}{*}{$\begin{array}{c}p- \\
\text { value }\end{array}$} \\
\hline & \multicolumn{2}{|c|}{$\begin{array}{c}\text { Yes } \\
\end{array}$} & \multicolumn{2}{|c|}{ No } & & & & & \\
\hline & $n$ & $(\%)$ & $n$ & $(\%)$ & $n$ & $(\%)$ & & & \\
\hline Total & 419 & $(96.3)$ & 16 & $(3.7)$ & 435 & $(100)$ & & & \\
\hline \multicolumn{10}{|l|}{ Gender } \\
\hline Male & 225 & $(94.5)$ & 13 & $(5.5)$ & 238 & $(54.7)$ & $4.72 *$ & 1 & 0.039 \\
\hline Female & 194 & $(98.5)$ & 3 & $(1.5)$ & 197 & $(45.3)$ & & & \\
\hline \multicolumn{10}{|l|}{ Education } \\
\hline No formal education & 51 & $(91.1)$ & 5 & $(8.9)$ & 56 & $(12.9)$ & $8.12 *$ & 2 & 0.010 \\
\hline Primary level (1-5 grades) & 316 & $(97.8)$ & 7 & $(2.2)$ & 323 & $(74.3)$ & & & \\
\hline Secondary level (6-10 grades) & 52 & $(92.9)$ & 4 & $(7.1)$ & 56 & $(12.9)$ & & & \\
\hline \multicolumn{10}{|l|}{ Occupation } \\
\hline House wife & 53 & $(100.0)$ & 0 & $(.0)$ & 53 & $(12.2)$ & $9.45^{*}$ & 6 & 0.087 \\
\hline Workers & 94 & $(96.9)$ & 3 & $(3.1)$ & 97 & $(22.3)$ & & & \\
\hline Day laborer & 24 & $(92.3)$ & 2 & $(7.7)$ & 26 & $(6.0)$ & & & \\
\hline Rickshaw Puller & 92 & $(96.8)$ & 3 & $(3.2)$ & 95 & $(21.8)$ & & & \\
\hline Jobless & 25 & $(96.2)$ & 1 & $(3.8)$ & 26 & $(6.0)$ & & & \\
\hline Small shop keeping & 105 & $(97.2)$ & 3 & $(2.8)$ & 108 & $(24.8)$ & & & \\
\hline Others & 26 & $(86.7)$ & 4 & (13.3) & 30 & $(6.9)$ & & & \\
\hline \multicolumn{10}{|l|}{ Marital status } \\
\hline Married & 367 & $(96.6)$ & 13 & $(3.4)$ & 380 & $(87.4)$ & $2.57 *$ & 2 & 0.277 \\
\hline Unmarried & 18 & $(90.0)$ & 2 & $(10.0)$ & 20 & $(4.6)$ & & & \\
\hline Divorced & 34 & $(97.1)$ & 1 & $(2.9)$ & 35 & $(8.0)$ & & & \\
\hline \multicolumn{10}{|l|}{ Family type } \\
\hline Nuclear & 373 & $(96.4)$ & 14 & $(3.6)$ & 387 & $(89.0)$ & $0.04 *$ & 1 & 0.693 \\
\hline Joint & 46 & $(95.8)$ & 2 & $(4.2)$ & 48 & $(11.0)$ & & & \\
\hline \multicolumn{10}{|l|}{ Monthly family income } \\
\hline$\leq 10,000 \mathrm{BDT}$ & 234 & $(96.3)$ & 9 & $(3.7)$ & 243 & $(55.9)$ & 0.01 & 1 & 0.975 \\
\hline$>10,000 \mathrm{BDT}$ & 185 & $(96.4)$ & 7 & $(3.6)$ & 192 & $(44.1)$ & & & \\
\hline \multicolumn{10}{|l|}{ Sleep status } \\
\hline$<7$ hours & 136 & $(97.8)$ & 3 & $(2.2)$ & 139 & $(32.0)$ & $3.99 *$ & 2 & 0.135 \\
\hline 7-9 hours & 278 & $(95.9)$ & 12 & $(4.1)$ & 290 & $(66.7)$ & & & \\
\hline$>9$ hours & 5 & $(83.3)$ & 1 & $(16.7)$ & 6 & $(1.4)$ & & & \\
\hline \multicolumn{10}{|l|}{ Tobacco smoking } \\
\hline Yes & 99 & $(98.0)$ & 2 & $(2.0)$ & 101 & $(23.2)$ & $1.07 *$ & 1 & 0.382 \\
\hline No & 320 & $(95.8)$ & 14 & $(4.2)$ & 334 & $(76.8)$ & & & \\
\hline \multicolumn{10}{|l|}{ Job loss due to COVID-19 } \\
\hline Yes & 417 & $(97.0)$ & 13 & $(3.0)$ & 416 & $(95.6)$ & $28.74 *$ & 1 & $<0.001$ \\
\hline No & 2 & $(40.0)$ & 3 & $(60.0)$ & 19 & $(4.4)$ & & & \\
\hline \multicolumn{10}{|c|}{ Experiencing food scarcity due to COVID-19 } \\
\hline Yes & 405 & $(97.4)$ & 11 & $(2.6)$ & 430 & $(98.9)$ & 45.29 & 1 & $<0.001$ \\
\hline \multirow[t]{2}{*}{ No } & 14 & $(73.7)$ & 5 & $(26.3)$ & 5 & $(1.1)$ & & & \\
\hline & Mean & $(S D)$ & Mean & $(S D)$ & Mean & $(S D)$ & $t$ & df & $\begin{array}{c}p- \\
\text { value }\end{array}$ \\
\hline Age & 44.9 & $(11.9)$ & 45.7 & $(14.0)$ & 45.0 & 12.0 & 0.06 & 1 & 0.803 \\
\hline Depression & 7.2 & $(4.4)$ & 5.0 & $(5.0)$ & 7.1 & $(4.4)$ & 3.86 & 1 & 0.050 \\
\hline PTSD & 15.2 & $(3.2)$ & 13.7 & $(7.2)$ & 15.1 & $(3.4)$ & 3.06 & 1 & 0.081 \\
\hline
\end{tabular}

Note:

$610 \mathrm{SD}=$ Standard deviation

611 BDT= Bangladeshi Taka

$612 *$ Fisher's Exact test

613

614 
Table 2. Multivariate regression analysis predicting depression and PTSD

\begin{tabular}{|c|c|c|c|c|c|c|c|c|}
\hline \multirow{2}{*}{ Characteristics } & \multicolumn{4}{|c|}{ Depression $^{1}$} & \multicolumn{4}{|c|}{ PTSD $^{2}$} \\
\hline & Mean & $(S D)$ & $S E$ & $\boldsymbol{\beta}$ & Mean & $(S D)$ & $S E$ & $\boldsymbol{\beta}$ \\
\hline \multicolumn{9}{|l|}{ Gender } \\
\hline Male & 6.4 & $(4.0)$ & & $\dagger$ & 14.9 & $(3.7)$ & & $\dagger$ \\
\hline Female & 8.1 & $(4.7)$ & 0.80 & $0.19 *$ & 15.4 & $(3.0)$ & 0.64 & 0.03 \\
\hline \multicolumn{9}{|l|}{ Age } \\
\hline $18-40$ years & 6.6 & $(4.0)$ & & $\dagger$ & 15.1 & $(3.1)$ & & $\dagger$ \\
\hline$>40$ years & 7.6 & $(4.7)$ & 0.43 & 0.06 & 15.2 & $(3.6)$ & 0.35 & 0.00 \\
\hline \multicolumn{9}{|l|}{ Education } \\
\hline Secondary level (6-10 grades) & 7.5 & $(4.4)$ & & $\dagger$ & 15.3 & $(3.6)$ & & $\dagger$ \\
\hline No formal education & 7.6 & $(5.9)$ & 0.81 & -0.06 & 15.6 & $(5.5)$ & 0.65 & -0.01 \\
\hline Primary level (1-5 grades) & 7.0 & $(4.1)$ & 0.63 & -0.11 & 15.0 & $(2.8)$ & 0.51 & -0.06 \\
\hline \multicolumn{9}{|l|}{ Occupation } \\
\hline House wife & 8.6 & $(5.3)$ & & $\dagger$ & 15.1 & $(2.8)$ & & $\dagger$ \\
\hline Workers & 6.9 & $(3.6)$ & 0.86 & -0.10 & 15.5 & $(2.9)$ & 0.69 & 0.00 \\
\hline Day laborer & 6.0 & $(5.0)$ & 1.31 & -0.03 & 14.5 & $(6.2)$ & 1.05 & -0.04 \\
\hline Rickshaw Puller & 6.9 & $(3.5)$ & 1.06 & 0.03 & 15.4 & $(3.4)$ & 0.85 & 0.10 \\
\hline Jobless & 11.3 & $(5.8)$ & 1.04 & $0.11 *$ & 16.2 & $(4.2)$ & 0.83 & 0.02 \\
\hline Small shop keeping & 6.3 & $(4.2)$ & 0.92 & -0.02 & 14.8 & $(2.9)$ & 0.74 & 0.02 \\
\hline Others & 6.4 & $(4.7)$ & 1.16 & -0.01 & 14.1 & $(3.3)$ & -0.84 & -0.06 \\
\hline \multicolumn{9}{|l|}{ Marital status } \\
\hline Married & 6.7 & $(3.9)$ & & $\dagger$ & 15.0 & $(3.4)$ & & $\dagger$ \\
\hline Unmarried & 6.3 & $(3.6)$ & 1.02 & -0.03 & 16.5 & $(4.2)$ & 0.81 & 0.09 \\
\hline Divorced & 12.1 & (6.9) & 0.87 & $0.20 * * *$ & 16.1 & $(3.0)$ & 0.69 & 0.05 \\
\hline \multicolumn{9}{|l|}{ Family type } \\
\hline Nuclear & 6.7 & $(4.0)$ & & $\dagger$ & 15.0 & $(3.3)$ & & $\dagger$ \\
\hline Joint & 10.5 & $(6.3)$ & 0.72 & $0.13 * *$ & 16.4 & $(4.0)$ & 0.58 & 0.09 \\
\hline \multicolumn{9}{|l|}{ Monthly family income } \\
\hline$>10,000 \mathrm{BDT}$ & 7.0 & $(4.5)$ & & $\dagger$ & 14.6 & $(2.9)$ & & $\dagger$ \\
\hline$\leq 10,000 \mathrm{BDT}$ & 7.2 & $(4.4)$ & 0.51 & 0.08 & 15.6 & $(3.7)$ & 0.41 & $0.17 * *$ \\
\hline \multicolumn{9}{|l|}{ Sleep status } \\
\hline 7-9 hours & 6.9 & $(4.5)$ & & $\dagger$ & 15.4 & $(3.7)$ & & $\dagger$ \\
\hline$<7$ hours & 7.5 & $(4.3)$ & 0.43 & 0.08 & 14.6 & $(2.7)$ & 0.34 & $-0.11 *$ \\
\hline$>9$ hours & 10.7 & $(4.6)$ & 1.75 & $0.09 *$ & 18.0 & $(1.9)$ & 1.40 & $0.11 *$ \\
\hline \multicolumn{9}{|l|}{ Tobacco smoking } \\
\hline No & 7.1 & $(4.6)$ & & $\dagger$ & 15.2 & $(3.5)$ & & $\dagger$ \\
\hline Yes & 7.3 & $(3.8)$ & 0.56 & $0.14 * *$ & 15.0 & $(2.9)$ & 0.45 & 0.00 \\
\hline \multicolumn{9}{|l|}{ Job loss due to COVID-19 } \\
\hline No & 6.5 & $(6.1)$ & & $\dagger$ & 12.6 & $(6.6)$ & & $\dagger$ \\
\hline Yes & 7.2 & $(4.3)$ & 1.05 & -0.01 & 15.3 & $(3.1)$ & 0.84 & $0.13 *$ \\
\hline \multicolumn{9}{|c|}{ Experiencing food scarcity due to the COVID-19 pandemic } \\
\hline No & 2.8 & $(3.0)$ & & $\dagger$ & 9.6 & $(7.3)$ & & $\dagger$ \\
\hline Yes & 7.2 & $(4.4)$ & 2.02 & 0.05 & 15.2 & $(3.3)$ & 1.62 & $0.14 * *$ \\
\hline \multicolumn{9}{|c|}{ Household income decreases due to the COVID-19 pandemic } \\
\hline No & 5.0 & $(5.0)$ & & $\dagger$ & 13.7 & $(7.2)$ & & $\dagger$ \\
\hline Yes & 7.2 & $(4.4)$ & 1.13 & 0.06 & 15.2 & $(3.2)$ & 0.36 & 0.02 \\
\hline \multicolumn{9}{|l|}{ Note: } \\
\hline \multicolumn{9}{|l|}{$\mathrm{SD}=$ Standard deviation } \\
\hline \multicolumn{9}{|l|}{$\mathrm{SE}=\mathrm{Standard}$ error } \\
\hline$\beta=$ Standardized regression coeff & cient & & & & & & & \\
\hline $\begin{array}{l}\mathrm{BDT}=\text { Bangladeshi Taka } \\
\dagger \text { Reference category }\end{array}$ & & & & & & & & \\
\hline Model summery (Depression): & $(20,414)=5$ & $3, p<0$. & $01, R_{\mathrm{A}}^{2}$ & $=0.17$ & & & & \\
\hline${ }^{2}$ Model summery (PTSD): $F_{(20,4}$ & $=3.33$ & 0.001 & ${ }^{2}$ Adj $=0.1$ & & & & & \\
\hline$* p<0.05, * * p<0.01, * * * p<0.001$ & & & & & & & & \\
\hline
\end{tabular}


Figure 1. Inclusion of the participants

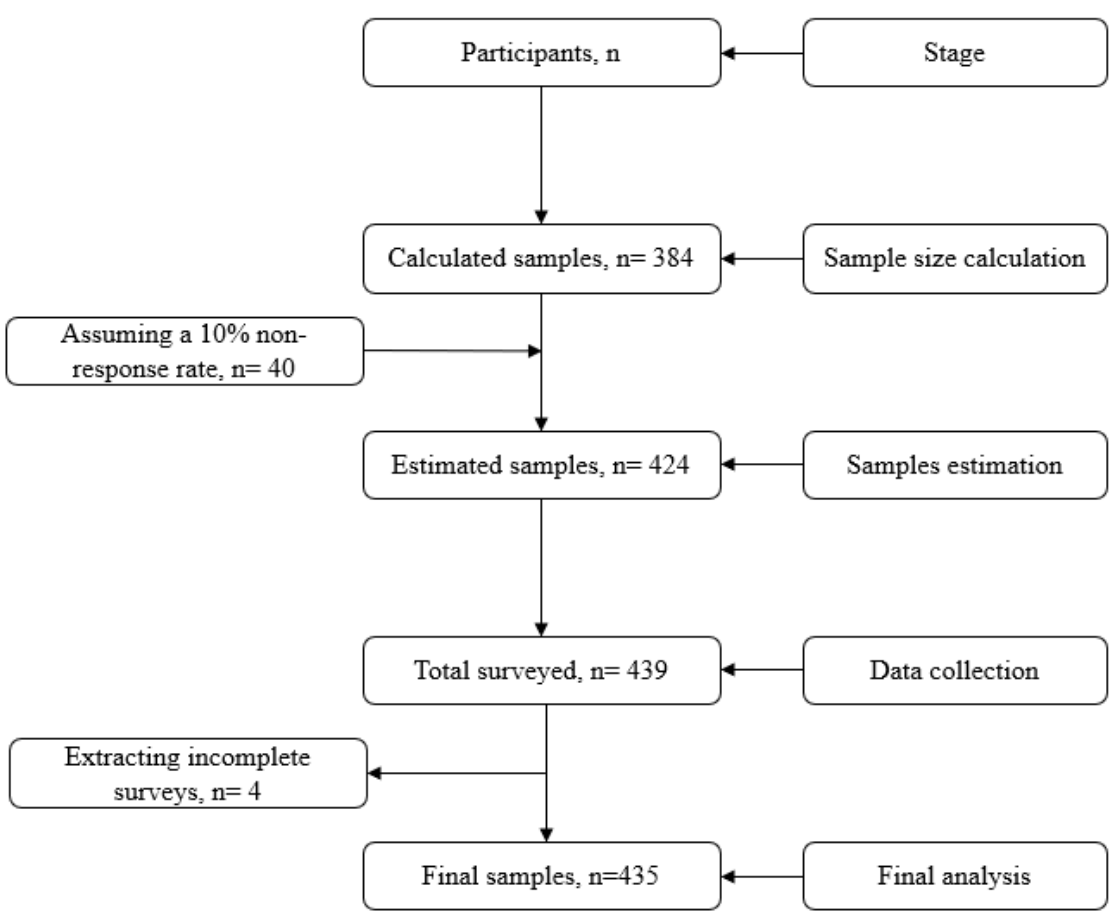

627 
Impoverished Urban-dwelling Individuals

Different depressive symptoms

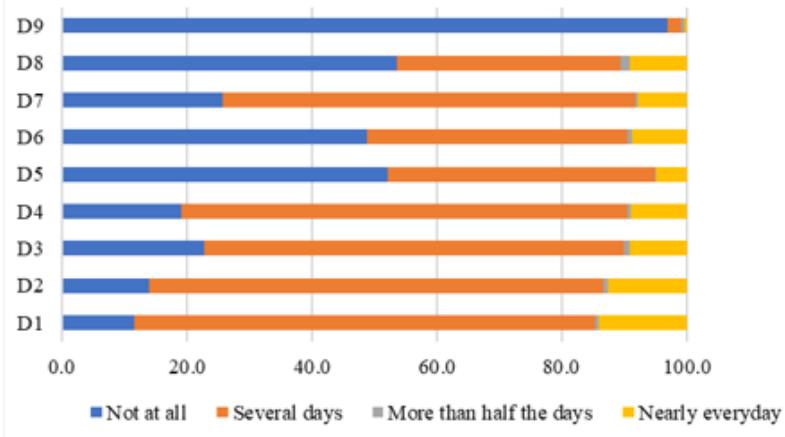

$\mathrm{D} 1=$ Little interest or pleasure in doing things

$\mathrm{D} 2=$ Feeling down, depressed, or hopeless

D3= Trouble falling or staying asleep, or sleeping too much

D4= Feeling tired or having little energy

D5 = Poor appetite or overeating

D6=Feeling bad about yourself or that you are a failure or have let yourself or your family down

D7 $=$ Trouble concentrating on things, such as reading the newspaper or watching television

D8= Moving or speaking so slowly that other people could have noticed. Or the opposite being so fidgety or restless that you have been moving around a lot more than usual

D $9=$ Thoughts that you would be better off dead, or of hurting yourself
Different PTSD symptoms

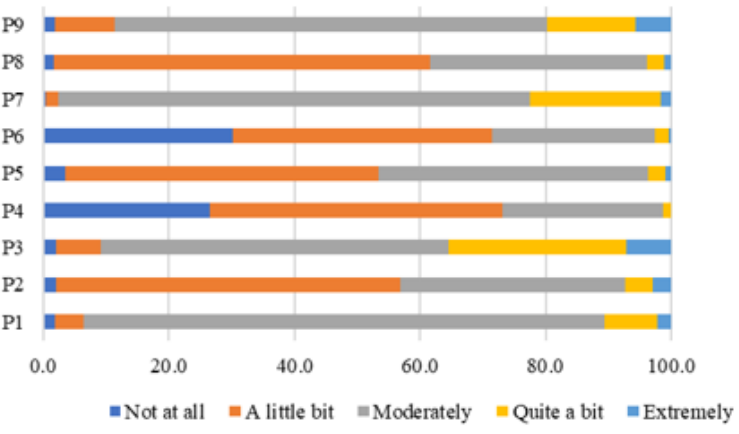

P1= Having "flashbacks", that is, you suddenly acted or felt as if a stressful experience from the past was happening all over again (for example, you re-experienced parts of a stressful experience by seeing, hearing, smelling, or physically feeling parts of the stressful experience)

$\mathrm{P} 2=$ Feeling very emotionally upset when something reminded you of a stressful experience

P3 = Trying to avoid thoughts, feelings, or physical sensations that reminded you of a stressful experience

P4= Thinking that a stressful event happened because you or someone else (who didn't directly harm you) did something wrong or didn't do everything possible to prevent it, or because of something about you

P5= Having a very negative emotional state (for example, you were experiencing lots of fear, anger, guilt, shame, or horror) after a stressful experience P6 = Losing interest in activities you used to enjoy before having a stressful experience P7 = Being "super alert", on guard, or constantly on the lookout for danger

P\&= Feeling jumpy or easily startled when you hear an unexpected noise

$\mathrm{P} 9=$ Being extremely irritable or angry to the point where you yelled at other people, got into fights, or destroyed things 